Emir Ćorović, vanredni profesor*

Departman za pravne nauke

Drăavni univerzitet u Novom Pazaru
Originalni naučni rad

UDK: 343.238(497.11)

Primljeno:1.7.2020.

Prihvaćeno:17.7.2020.

https://doi.org/10.47152/rkkp.58.1.2.1

\title{
POVRAT U KRIVIČNOM ZAKONIKU SRBIJE: KRITIČKI OSVRT NA NJEGOVO NORMATIVNO UREĐENJE
}

Zakonom o izmenama i dopunama Krivičnog zakonika Srbije iz maja meseca 2019. godine, koje su stupile na snagu 1. decembra iste godine, promenjen je koncept povrata koji je postojao u našem krivičnom pravu. Naime, pored tzv. ,običnog “ povrata, koji je sada regulisan na posve drugačiji način u odnosu na prijašnju legislativu, posebno je normiran i višestruki povrat. Uz ove dve forme povrata, Krivični zakonik Srbije poznaje i specijalni povrat, koji je regulisan u okviru odredbe o ublažavanju kazne, tačnije kao jedan od zakonskih razloga koji isključuje ublažavanje kazne. Zakonska regulativa pomenutih oblika povrata nije najpreciznija i može stvarati odgovarajuće dileme prilikom primene ovih odredaba u praksi. Otuda će se u radu ukazati na slabost $i$ nelogičnost normativnog uređenja pojedinih formi povrata, sve s ciljem poboljšanja njihove zakonske regulative.

Ključne reči: povrat, višestruki povrat, specijalni povrat.

e-mail: ecorovic@np.ac.rs 


\section{Uvodna razmatranja}

Izmenama i dopunama Krivičnog zakonika Srbije (u daljem tekstu: KZ) ${ }^{1}$ iz maja meseca 2019. godine, a koje su stupile na snagu 01.12.2019. godine, došlo je do promena odredaba koje regulišu povrat. Do tada, povrat je predstavljao fakultativnu otežavajuću okolnost prilikom odmeravanja kazne. ${ }^{2}$ Sadašnji zakonski tekst, pak, eksplicitno razlikuje (obični) povrat (član 55. KZ) i višestruki povrat (član 55a KZ), predviđajući njihovo različito pravno dejstvo. Ovim odredbama zakonodavac je nastojao da institut povrata precizno reguliše, mada su i pored toga određena pitanja ostala otvorena.

Nezavisno od navedenih odredaba o običnom i višestrukom povratu, KZ poznaje još i specijalni povrat, koji je uveden novelama KZ 2009. godine u vezi sa institutom zabrane ublažavanja kazne. Za razliku od (običnog) povrata i višestrukog povrata, koje zakonodavac reguliše u posebnim članovima, specijalni povrat ne uživa takvu ,autonomnost“. Naime, specijalnom povratu nije posvećen poseban član, već je isti regulisan u članu 57. KZ koji se odnosi na granice ublažavanja kazne, preciznije u stavu 3. navedenog člana, kojim se isključuje mogućnost ublažavanja kazne u slučaju osude za isto ili istovrsno krivično delo.

Čak i ovako grub osvrt na mesto povrata odnosno njegovih vrsta u KZ, ukazuje na legislativnu neprincipijelnost u njegovom sistematizovanju. S jedne strane, dve forme povrata (obični i višestruki) imaju svoje posebno mesto, tj. posebne članove koji su im posvećeni, i (relativno) preciznu regulativu, dok se s druge strane odreba o specijalnom povratu nalazi u članu koji se odnosi na granice ublažavanja kazne, tj. na mestu koji je posvećen sasvim drugom krivičnopravnom institutu i, kao što će se videti, nije regulisan na zadovoljavajući način, tačnije regulisan je prilično neprecizno. Ako je zakonodavac novelama od 2019. godine posebno regulisao obični i višestruki povrat, trebalo je onda i da posebno reguliše specijalni povrat, ako je za tim uopšte bilo potrebe (o čemu će biti reči), čime bi odredbe o ovom institutu bile preglednije.

1 Krivični zakonik, Službeni glasnik RS, br. 85/2005, 88/2005 - ispr., 107/2005 - ispr., 72/2009, 111/2009, 121/2012, 104/2013, 108/2014, 94/2016 i 35/2019.

2 Do izmena i dopuna iz 2019. godine, odredba člana 55. KZ je glasila: „Kad sud odmerava kaznu učniocu za krivično delo koje je učinio posle izdržane, oproštene ili zastarele kazne ili oslobođnja od kazne, po proteku roka za opozivanje uslovne osude ili posle izrečene sudske opomene, može tu okolnost uzeti kao otežavajuću, ceneći pri tom posebno težinu ranije učinjenog krivičnog dela, da li je ranije delo iste vrste kao i novo delo, da li su oba dela učinjena iz istih pobuda, okolnosti pod kojima su dela učinjena i koliko je vremena proteklo od ranije osude, odnosno od izrečene, oproštene ili zastarele kazne, osloboenja od kazne, od proteka roka za opozivanje ranije uslovne osude ili od izrečene sudske opomene". 


\section{Obični ${ }^{3}$ povrat iz člana $55 . \mathrm{KZ}$}

Običan povrat prema članu 55. stav 1 . KZ postoji ukoliko su kumulativno ispunjeni sledeći uslovi: (1) da je učinjeno umišljajno krivično delo, (2) da se i ranija osuda odnosi na umišljajno krivično delo i (3) da od ranije osude ili izdržane kazne nije proteklo pet godina.

Jasno je da se obični povrat odnosi samo na umišljajna krivična dela. Znači, i ranije i novoučinjeno krivično delo moraju biti učinjeni sa umišljajem (Stojanović, 2020: 40) odnosno, drugačije rečeno, nehat je nespojiv sa konstrukcijom običnog povrata u smislu člana 55. KZ. Prema tome, kod običnog povrata ,uslov u pogledu krivičnih dela je vezan isključivo za oblik krivice, te nije od značaja na koju kaznu, ili krivičnu sankciju je učinilac osuđen za prethodno delo“ (Đokić, 2019: 322). Obični povrat će postojati i ukoliko novo odnosno ranije krivično delo (ili oba) potpadaju pod konstrukciju krivičnog dela kvalifikovanog težom posledicom, ali samo onda kada je osnovno delo iz takve konstrukcije umišljajno (u odnosu na težu posledicu se po pravilu traži nehat). Naime, prema članu 27. KZ teža posledica (koja je po pravilu nehatna) mora proizaći iz krivičnog dela (osnovno delo), a ono može biti kako umišljajno, tako i nehatno. Ali, kada je reč o povratu u smislu člana 55. KZ, takvo krivično delo mora biti umišljano u smislu prethodno rečenog.

Za postojanje povrata potrebno je da je novo krivično delo učinjeno , u ro$k u$ “ od pet godina od ranije osude odnosno izdržane kazne (po zakonskom tekstu: da od ranije osude ili izdržane kazne nije proteklo pet godina). Petogodišnji rok od ranije osude odnosno izdržane kazne se računa do momenta izvršenja novog krivičnog dela, a ne do momenta otkrivanja ili početka suđenja za to novo delo (Jocić, 2019: 234-235). Naime, povrat po definiciji predstavlja ponovno vršenje krivičnog dela od strane već osuđivanog učinioca (Ćorović, 2015: 149), što znači da u momentu vršenja novog krivičnog dela prema učiniocu mora postojati pravnosnažna osuđujuća presuda za ranije krivično delo. Ovaj rok se, prema slovu zakona, ceni od ranije osude odnosno izdržane kazne. Na koji način protumačiti izraz „osuda“? Valja napomenuti da je pre izmena iz 2019. godine odredba člana 55. KZ bila preciznija i izričito se odnosila na osude kojima je izrečena neka od kazni odnosno kada je učinilac oslobođen od kazne, kao i kada su izrečene mere upozorenja (uslovna osuda i sudska opomena). Jasno je bilo da ranije izricanje mera bezbednosti i vaspitnih mera nije potpadalo pod povrat. Sada je,

3 Formulacija „obični“ se ne koristi u zakonskom tekstu za označavanje blaže forme povrata, već se za njega jednostavno koristi naziv ovog institua - ,povrat“. Međutim, po svojoj sadržini, kao i na osnovu njegovog odnosa prema višestrukom povratu, može se reći da se radi o konstrukciji „običnog" povrata. Naime, obični povrat podrazumeva postojanje jedne ranije osude (zato se nekada naziva i jednostrukim), dok višestruki podrazumeva postojanje više (barem dve) ranije osude. 
međutim, stilistika odredbe člana 55. stav 1. KZ drugačija, jer se samo govori o ranijoj osudi (i izdržanoj kazni). Zato se i otvara pitanje s početka ovog pasusa.

Možda bi u tumačenju izraza „osuda“ trebalo poći od pojma ,osuđenog“" koji je određen u članu 2. stavu. 1. tački 4. Zakonika o krivičnom postupku? ${ }^{4}$ Osuđeni prema navedenoj odredbi označava lice za koje je pravnosnažnom odlukom suda utvrđeno da je učinilac krivičnog dela ili protivpravnog dela određenog u zakonu kao krivično delo, osim ako se na osnovu odredaba KZ smatra neosuđivanim. Ova odredba se s pravom kritikuje iz razloga što osuđenim licem smatra i neuračunljivog učinioca protivpravnog dela koje je zakonom određeno kao krivično delo, jer to lice ne postupa skrivljeno pa kao takvo ne bi trebalo biti subjekt osude (o tome: Brkić, 479-480). Međutim, sa stanovišta pozitivnog prava ipak se može postaviti pitanje da li se pravnosnažno rešenje o izricanju psihijatrijskih mera bezbednosti iz čl. 81. i 82. KZ neuračunljivim učiniocima može smatrati osudom u smislu člana 55. KZ? Na ovo pitanje treba odrečno odgovoriti bez obzira što se po ZKP-u ova lica smatraju osuđenicima, jer se u članu 55. stav 1. KZ govori o „ranijoj osudi za umišljajno krivično delo", što znači da se mora raditi o osudi kojom je utvrđena učiniočeva krivica, čega nema u slučaju kada je ranije učinjeno protivpravno delo od strane neuračunljivog lica. Ni ranije izricanje vaspitnih mera učiniocu ne može se smatrati osudom u smislu člana 55. KZ jer se ova sankcija izriče odlukom u formi rešenja u čijoj izreci se samo navodi koja se vaspitna mera izriče, s tim da se maloletnik neće oglašavati krivim za krivično delo koje mu se stavlja na teret. ${ }^{5}$ Ukoliko je učiniocu krivičnog dela ranije pravnosnažno izrečena neka od psihijatrijskih mera bezbednosti ili vaspitna mera, takva okolnost bi mogla biti relevantna za odmeravanje kazne u smislu člana 54. KZ (raniji život). ${ }^{6}$

U tom smislu trebalo bi uzeti da izraz osuda podrazumeva postojanje pravnosnažne presude kojom je izrečena kazna ili je učinilac oslobođen od kazne, odnosno kojom je izrečena uslovna osuda ili sudska opomena (Jocić, 2019: 234). Iako navedeno deluje poprilično jasno, potrebno je razlikovati nekoliko momenata koji su od značaja za početak i istek navedenog petogodišnjeg roka, a koji zavise pre svega od vrste krivične sankcije (kazna, oslobođenje od kazne ili neka mera upozorenja) na koju je neko lice ranije osuđeno.

4 Zakonik o krivičnom postupku, Službeni glasnik RS, br. 72/2011, 101/2011, 121/2012, 32/2013, 45/2013, 55/2014 i 35/2019.

5 Član 78. stav 3. Zakona o maloletnim učiniocima krivičnih dela i krivičnopravnoj zaštiti maloletnih lica-ZMUKD, Službeni glasnik RS, br. 85/2005.

6 Kada je reč o vaspitnim merama potrebno je voditi računa o članu 27. ZMUKD prema kojem se podaci o izrečenim vaspitnim merama mogu se dati samo sudu, javnom tužilaštvu i organu starateljstva, s tim da se podaci o vaspitnim merama izrečenim za krivična dela za koja je propisana novčana kazna ili kazna zatvora do tri godine ne mogu davati ako je lice na koje se podaci odnose navršilo dvadeset jednu godinu. 
1) Ukoliko je učinilac ranije osuđen na kaznu zatvora, taj rok teče od trenutka kada je ova kazna u celosti izdržana, tačnije kada je osuđeni otpušten sa njenog izdržavanja. ${ }^{7}$ U slučaju uslovnog otpusta petogodišnji rok počinje da teče od isteka uslova (Jocić, 2019: 235), jer je u članu 46. stavu 4. KZ propisano da će se smatrati da je osuđeni izdržao kaznu ako uslovni otpust ne bude opozvan. Kada je reč o osuđenom na doživotni zatvor, uslovni otpust ističe nakon petnaest godina od dana uslovnog otpuštanja (član 47. stav 7. KZ), tako da pomenuti petogodišji rok teče od tog trenutka.

Opravdano se ističe da neće postojati povrat u smislu člana 55. KZ ukoliko neko lice učini krivično delo za vreme uslovnog otpusta (Jocić, 2019: 235), upravo zbog toga što kazna formalo-opravno nije izdržana. U tom slučaju do opoziva uslovnog otpusta mora (obavezni) ili može (fakultativni) doći, gde će se učiniocu, primenom odredaba za izricanje jedinstvene kazne za krivično delo u sticaju (član 60. KZ) i odredaba o odmeravanju kazne osuđenom licu (član 62. KZ), izreći jedinstvena kazna (član 47. st. 1., 2. i 4. KZ), odnosno doći će, ukoliko ne dođe do opoziva, do njegovog produženja za vreme koje je osuđeni proveo na izdržavanju kazne po novoj osudi (član 47. stav 5. KZ).

Potrebno je, s tim u vezi, voditi računa o zatvorskim kaznama izrečenim u trajanju do šest meseci. Naime, za ove kazne zakonska rehabilitacija nastupa $u$ roku od tri godine od dana kad je ta kazna izvršena, zastarela ili oproštena, pod uslovom da učinilac ne učini novo krivično delo. Ukoliko nastupi rehabilitacija, dolazi do brisanja osude i prestanka svih njenih pravnih posledice, a osuđeni se smatra neosuđivanim (član 97. stav 1. KZ). To znači da se petogodišnj rok u kome se ceni povrat faktički skraćuje: na primer, učiniocu umišljajnog krivičnog dela izrečen je zatvor u trajanju od šest meseci; nakon tri godine, pod uslovom da učinilac nije osuđivan za novo krivično delo, dolazi do rehabilitacije sa svim njenim posledicama; u ovom i sličnim slučajevima rok za ocenu povrata je de facto „skraćen“" sa pet na tri godine. Naravno, u svakom konkretnom slučaju se mora utvrditi da li su ispunjeni uslovi za rehabilitaciju, jer je moguće da, bez obzira na visinu ranije kazne zatvora, ne postoje uslovi za zakonsku rehabilitaciju niti, pak, za sudsku rehabilitacija u slučaju višestruke osuđivanosti, usled neispunjenosti uslova iz člana 98. stav 1. i člana 100. KZ. ${ }^{8}$

7 Prema članu 178. Zakona o izvršenju krivičnih sankcija - ZIKS (Službeni glasnik RS, br. 55/2014 i 35/2019) osuđeni se otpušta iz zavoda onog dana kada mu je istekla kazna, a ako istek kazne pada u subotu, nedelju ili u dane državnih praznika, osuđeni se otpušta poslednjeg radnog dana koji prethodi tim danima.

8 Prema članu 97. stav 1. KZ zakonska rehabilitacija se daje samo licima koja pre osude na koju se odnosi rehabilitacija nisu bila osuđivana ili koja su se po zakonu smatrala neosuđivanim. Znači, to su prvoprestupnici, odnosno lica koja su već rehabilitovana, dok se prema članu 100. KZ sudska rehabilitacija može dati i licu koje je više puta osuđivano, pod uslovom da su ispunjeni uslovi za 
Iako se u članu 55. stavu 1. govori samo o „,izdržanoj kazni“, treba uzeti da se petogodišnji rok za ocenu povrata računa i ukoliko izrečena kazna zatvora nije izdržana, već je zastarela ili oproštena. Kazna zatvora redovno „prestaje“ njenim izdržavanjem, a drugi načini njenog prestanka su zastarelost, amnestija i pomilovanje. Ovo shvatanje ima uporište u logičkom tumačenju, jer ukoliko se predmetni rok računa od izdržane kazne, argumentum a fortiori (maiore ad minus) računaće se i od trenutka kada je kazna zastarela odnosno oproštena (tj. obuhvaćena amnestijom ili pomilovanjem).

2) U slučaju novčane kazne, rada u javnom interesu i oduzimanja vozačke dozvole, kada su izrečene kao glavne kazne, nije najjasnije od kojeg trenutka teče pomenuti petogodišnji rok za ocenu povrata. Da li od trenutka osude, tj. pravnosnažnosti presude kojima su izrečene, ili od trenutka kada su ove kazne „izdržane"?

Po jednom mišljenju bi, u ovom slučaju, računanje rokova valjalo upodobiti računanju zatvorske kazne, tako da rok teče od potpuno naplaćene novčane kazne ili izdržane kazne zatvora ako je novčana kazna njome zamenjena, što bi trebalo da važi i za rad u javnom interesu, kao i za oduzimanje vozačke dozvole, jer se i one mogu zameniti kaznom zatvora (Jocić, 2019: 235). Pitanje je, međutim, da li ovo shvatanje ima uporište u KZ? Odgovor na postavljeno pitanje zavisi od značenja pojma ,izdržana kazna“.

Ako se pogledaju relevantne odredbe KZ, formulacije ,izdržana“, ,izdrŽavati“, ,izdržao“ i slično, vezuju se, načelno, za krivične sankcije koje obuhvataju lišenje slobode, odnosno za druge mere koje se sastoje od lišenja slobode. ${ }^{9}$ Imajući u vidu da su zatvor i doživotni zatvor jedine kazne koje se manifestuju u lišenju slobode, to bi se u ovom slučaju pojam ,izdržana“ mogao odnositi samo na te kazne, ne i na ostale, s obzirom da se one ne sastoje od lišenja slobode. Jezički posmatrano, ne može se reći ,izdržati novčanu kaznu, izdržati rad u javnom intersu ili izdržati oduzimanje vozačke dozvole“. Za ispunjenje (egzekutivu) ovih kazni se koriste drugi pojmovi. Tako, kod novčane kazne se koriste

zakonsku, odnosno sudsku rehabilitaciju u pogledu svakog krivičnog dela za koje je osuđeno (Ćorović, 2015: 300-303).

9 Navedeni pojmovi se, pored odredbe o povratu iz člana 55. KZ, koriste kod odredaba koje su posvećene: posebnim uslovima za krivično gonjenje za krivično delo učinjeno u inostranstvu (član 10. KZ), uračunavanju pritvora i kazne izdržane u inostranstvu (član 11. KZ), zatvoru (član 45 KZ), uslovnom otpustu (član 46. KZ), opozivu uslovnog otpusta (član 47. KZ), višestrukom povratu (član 55a KZ), odmeravanju kazne osuđenom licu (član 62. KZ), uračunavanju pritvora i ranije kazne (član 63. KZ), opozivanju uslovne osude zbog novog krivičnog dela (član 67. KZ), obaveznom psihijatrijskom lečenju i čuvanju u zdravstvenoj ustanovi (član 81 . KZ), početku i trajanju pravnih posledica osude (član 96. KZ), sudskoj rehabiltaciji (član 99. KZ), prestanku pravnih posledica osude (član 101. KZ), sadržaju i davanju podataka iz kaznene evidencije (član 102. KZ). 
formulacija ,izvršenje“" i ,plaćanje“ (čl. 51., 63 st. 3. KZ), ${ }^{10}$ kod rada u javnom interesu „obavlja“ i ,ispunjava“ (član 52. KZ), a kod oduzimanja vozačke dozvole formulacija „,dok traje kazna oduzimanja vozačke dozvole“" (član 53. stav 4. KZ). Genusni pojam koji obuhvata sve navedene oblike „,ispunjenja“ (egzekutive) navedenih kazni jeste pojam ,,izvršenja“ (on se koristi u zakonima kojima se reguliše izvršenje krivičnih sankcija, ${ }^{11}$ ali i u, na primer, članu 98. stava 2. tačka 3. $\mathrm{KZ}^{12}$ ).

Ako se uzme u obzir rečeno, zaključuje se da je kod odredbe o povratu zakonodavac samo izdvojio kaznu zatvora od ostalih osuda, jer se jedino kod ove kazne, a povodom toka roka relevantnog za povrat, uzima u obzir trenutak od kada je ona izdržana. Argumentum a contrario, ukoliko je izrečena neka druga kazna, relevantan je trenutak ranije osude, odnosno trenutak kada je ranija presuda postala pravnosnažna, a ne kada je novčana kazna, rad u javnom interesu ili oduzimanje vozačke dozvole izvršeno.

U slučaju novčane kazne, rada u javnom interesu i oduzimanja vozačke dozvole zakonska rehabilitacija nastupa u roku od tri godine od dana kad je ta kazna izvršena, zastarela ili oproštena, pod uslovom da učinilac ne učini novo krivično delo, tako da i povodom ovih kazni dolazi do faktičkog skraćenja roka relevantnog za procenu postojanja povrata, a u skladu sa prethodno rečenim.

3) Prethodno pravilo bi trebalo važiti i ukoliko je izrečena uslovna osuda, tj. rok počinje da teče od trenutka osude, odnosno pravnosnažnosti presude kojom je izrečena ova mera upozorenja, s tim da se tu mora „uvesti“ jedan korektivni kriterijum.

Naime, ukoliko je učinilac za vreme perioda provere izvršio krivično delo, usled čega dođe do opoziva uslovne osude (bilo obaveznog bilo fakultativnog),

10 Odnos između ovih formulacija je dobro predstavljen upravo kod člana 63. stava 3. KZ: „Zatvor ili novčana kazna koju je osuđeni izdržao, odnosno platio za prekršaj ili privredni prestup, kao i kazna ili disciplinska mera lišenja slobode koju je izdržao zbog povrede vojne discipline uračunava se u kaznu izrečenu za krivično delo čija obeležja obuhvataju i obeležja prekršaja, privrednog prestupa, odnosno povrede vojne discipline".

11 ZIKS reguliše izvršenje kazne zatvora (čl. 43.-186.), izvršenje novčane kazne (čl. 187.-193.) i izvršenje oduzimanja vozačke dozvole (član 194.), dok Zakon o izvršenju vanzavodskih sankcija i mera - ZIVSM (Službeni glasnik RS, br. 55/2014 i 87/2018) reguliše izvršenje rada u javnom interesu (čl. 38-43.). ZIKS na 33 mesta koristi formulaciju ,izdržavanje“ i sl., od toga u 32 slučaja vezano za kaznu zatvora, a u jednom za obavezno psihijatrijsko lečenje i čuvanje u zdravstvenoj ustanovi, koja je takođe zavodska sankcija. ZIVSM ovaj pojam koristi 4 puta, od toga 3 puta za „kućni zatvor“, i jednom kod odredbe posvećene uslovnom otpustu (prema tome, opet vezano za kaznu zatvora).

12 Pomenuta odredba glasi: „lice koje je osuđeno na novčanu kaznu, kaznu rada u javnom interesu, oduzimanja vozačke dozvole ili kaznu zatvora do šest meseci, u roku od tri godine od dana kad je ta kazna izvršena, zastarela ili oproštena, ne učini novo krivično delo“. 
onda se u toj situaciji ranija osuda ne može ceniti prema članu 55. KZ, već će se izreći jedinstvena kazna za krivična dela učinjena u sticaju (član 67. st. 1., 2, i 3 KZ). Ovo iz razloga što se novo krivično delo ne može dvostruko vrednovati i kao razlog za opoziv uslovne osude, gde se primenjuju odredbe o sticaju, i kao povrat u smislu člana 55. KZ. Prema tome, primeniće se pravila o opozivu uslovne osude koja za sobom povlače primenu odredaba o odmeravanju jedinstvene kazne za krivična dela učinjena u sticaju.

Imajući u vidu da se povrat odnosi samo na umišljajna krivična dela, za novo krivično delo se svakako ne bi mogla izreći uslovna osuda na osnovu odredbe člana 66. stava 3. KZ, koji predviđa da se uslovna osuda se ne može izreći ako nije proteklo više od pet godina od pravnosnažnosti osude kojom je učiniocu izrečena kazna zatvora ili uslovna osuda za umišljajno krivično delo.

Ukoliko pak, učinilac u vreme perioda provere učini krivično delo, a sud se, u slučaju fakultativnog opoziva, ipak odluči da prijašnju uslovnu osudu ne opozove, tek onda ima mesta primeni odredbe člana 55. KZ. Naime, u ovom slučaju nema dvostrukog vrednovanja, jer prema učiniocu nisu primenjene odredbe o sticaju, tako da ima mesta primeni člana 55. KZ.

Ovde treba voditi računa i o članu 70. KZ. Prema stavu 1. ovog člana uslovna osuda se može opozvati u toku vremena proveravanja, a ako osuđeni u tom vremenu učini krivično delo koje povlači opozivanje uslovne osude, a to je presudom utvrđeno tek posle isteka vremena proveravanja, uslovna osuda može se opozvati najkasnije u roku od jedne godine od dana kad je proteklo vreme proveravanja. ${ }^{13}$ To dalje znači da se protekom tog roka uslovna osuda ne može opozvati, s tim da će se ranija uslovna osuda ceniti kao ranija osuda relevantna za povrat, pod uslovom da nije proteklo pet godina od pravnosnažnosti presude kojoj je uslovna osuda izrečena.

Kod uslovne osude takođe, a u vezi sa postojanjem ranije osude, treba voditi računa da li je nastupila zakonska rehabilitacija. Prema članu 98. stav 1. tačka 2. KZ zakonska rehabilitacija nastupa ako osuđeni u roku proveravanja i u roku od godinu dana po isteku roka proveravanja, ne učini novo krivično delo. To znači da i u slučaju ove krivične sankcije može doći do faktičkog skraćenja roka relevantnog za ocenu povrata. Na primer, učiniocu je određen rok provere od jed-

13 „Po nalaženju Vrhovnog kasacionog suda odluka o opozivu uslovne osude mora biti pravnosnažna u dodatnom roku od jedne godine od dana kada je proteklo vreme proveravanja po ranijoj osudi, jer rok za opozivanje uslovne osude propisan članom 70. stav 1. KZ ima prekluzivan karakter s obzirom na to da se njegovim protekom uslovna osuda više ne može opozvati ni pod kakvim uslovima“" (presuda Vrhovnog kasacionog suda, Kzz 102/2012 od 05.12.2012. godina), https:// www.vk.sud.rs/sr-lat/kzz-1022012-povrede-krivi\%C4\%8Dnog-zakona-uslovna-osuda (pristup, 16.04.2020. godine). 
ne godine; ukoliko u tom roku i o roku od jedne godine od isteka perioda provere ne učini novo krivično delo, rehabilitacija će nastupiti po sili zakona; u ovom primeru to znači da je potrebno da prođu dve godine od pravnosnažnosti presude da bi se jedan takav učinilac smatrao neosuđivanim, čime se de facto smanjuje period relevantan za ocenu povrata.

4) U slučaju da je učinilac presudom oslobođen od kazne, ili mu je izrečena sudska opomena, rok teče od pravnosnažnosti ovih presuda. Međutim, kod ovih sankcija zakonska nastupa u roku od godinu dana od pravnosnažnosti presude, pod uslovom da učinilac ne učini novo krivično delo. Ukoliko nastupi rehabilitacija, opet važi prethodno rečeno, tj. da je učinilac neosuđivan, tako da i u ovom slučaju nema mesta primeni petogodišnjeg roka relevantnog za povrat, odnosno dolazi do njegovog faktičkog skraćenja.

Ono što u vezi sa odredbom člana 55. KZ može biti konfuzno, jeste dejstvo običnog povrata. Naime, prema stavu 1. ovog člana obični povrat predstavlja obaveznu otežavajuću okolnost, dok se prema stavu 2. njegovo dejstvo odnosi na zabranu ublažavanja kazne. Izgleda da je zakonodavac kod običnog povrata „pomešao“ dejstva dva različita instituta - dejstvo obavezne otežavajuće okolnosti i dejstvo zabrane ublažavanja kazne. Zato se moraju pojasniti dejstva ova dva instituta (Ćorović, 2020: 166).

Obavezna otežavajuća okolnost predstavlja okolnost koja je unapred vrednovana od strane zakonodavca kao otežavajuća i koju sud, ukoliko je utvrdi, mora (tj. obavezan je) uzeti u obzir prilikom odmeravanja kazne. U krivičnom pravu Srbije je još 2012. godine uvedena, po prvi put, jedna obavezna otežavajuća okolnost. Reč je o članu 54a. KZ koji je naslovljen kao ,posebna okolnost za odmeravanje kazne za krivično delo učinjeno iz mržnje“. Po ovoj odredbi sud će (što je imperativna odredba), ukoliko je je krivično delo učinjeno iz mržnje zbog pripadnosti rasi i veroispovesti, zatim zbog nacionalne ili etničke pripadnosti, pola, seksualne orijentacije ili rodnog identiteta drugog lica, tu okolnost ceniti kao otežavajuću okolnost, osim ako ona nije propisana kao obeležje krivičnog dela. Međutim, iako se radi o obaveznoj otežavajućoj okolnosti to ne znači da će se učiniocu nužno izreći neka teža kazna. Naime, u konkretnom slučaju sud može pored obavezne otežavajuće okolnosti (u pomenutom primeru - mržnja) utvrditi i niz olakšavajućih okolnosti na osnovu opštih pravila o odmeravanju kazne iz člana 54. KZ. Ne treba zaboraviti da se otežavajuće i olakšavajuće okolnosti cene po analitičko-sintetičkom metodu. „To znači da bi sud na osnovu opšteg utiska, polazeći od propisane kazne, trebalo da dođe do jedne polazne osnove, do neke prosečne, orijetacione kazne i onda da je poveća i snižava nakon pažljivog pojedinačnog vrednovanja svake olakšavajuće i otežavajuće okol- 
nosti““ (Stojanović, 2009: 213). Štaviše, nije isključena mogućnost i da sud dâ „prevagu“ olakšavajućim okolnostima, tj. da ih utvrdi kao „,naročito olakšavajuće“ i da u konkretnom slučaju ublaži kaznu ukoliko to ukazuje da se sa ublaženom kaznom može postići svrha kažnjavanja (član 56. stav 1. tačka 3. KZ). Jer, postojanje neke otežavajuće okolnosti „,u načelu ne isključuje mogućnost ublažavanja kazne i (da) to zavisi od toga o kakvim otežavajućim okolnostima se radi i u kakvom su odnosu prema naročito olakšavajućim okolnostima, a posebno od toga kakav značaj imaju za ostvarenost uslova da se i ublaženom kaznom može postići svrha kažnjavanja“ (Delić, 2010: 189).

S druge strane, dejstvo zabrane ublažavanja kazne se manifestuje u isključenju mogućnosti izricanja kazne ispod posebnog zakonskog minimuma ili blaže vrste kazne. U krivično zakonodavstvo Srbije ova zabrana je uvedena još 2009. godine i nalazi se u članu 57. KZ. Prema toj odredbi zabrana ublažavanja kazne se odnosi na osudu za taksativno navedena dela (stav 2. navedenog člana) odnosno za slučaj specijalnog povrata (stav 3. navedenog člana). Međutim, specijalnom povratu se ne daje karakter obavezne otežavajuće okolnosti, već se naprosto kaže da se kazna ne može ublažiti učiniocu krivičnog dela koji je ranije osuđivan za isto ili istovrsno krivično delo.

Ono što je kod odredbe člana 55. KZ dobro učinjeno jeste to što je zabrana ublažavanja kazne, kao jedna inače sporna mogućnost koja se kritikuje u domaćoj teoriji, ograničena samo na tzv. sudsko ublažavanje kazne. To znači da se i u slučaju običnog povrata kazna može ublažiti u slučaju kada to zakon predviđa (tzv. zakonsko ublažavanje kazne - na primer kod prekoračenja nužne odbrane ili krajnje nužde, kod pokušaja, bitno smanjene uračunljivosti, kod kompulzivne sile i pretnje itd.), odnosno u slučaju kada zakon predviđa da se učinilac može osloboditi od kazne, a sud ga ne oslobodi od kazne (na primer prekoračenje nužne odbrane u slučaju jake razdraženosti ili prepasti, prekoračenje krajnje nužde pod naročito olakšavajućim okolnostima, nepodobnog pokušaja, dobrovoljnog odustanka itd.).

Iz rečenog može se zaključiti da je kod običnog povrata zakonodavac vrednovao raniju osuđivanost (koja se odnosi samo na umišljajna krivična dela) kao obaveznu otežavajuću okolnost (pod uslovom da je i novo krivično delo umišljajno i da od ranije osude ili izdržane kazne nije proteklo pet godina), sa krajnjim dejstvom koje se manifestuje u zabrani sudskog ublažavanja kazne. Međutim, nije bilo nužno, a s druge strane bilo bi i principijelnije (da bi se osiguralo jednoobrazno razumevanje zakonskih formulacija kod različitih instituta), da zakonodavac ističe obe ove okolnosti. Ako je bila intencija da se obični povrat ceni kao obavezna otežavajuća okolnost, dovoljna je bila postojeća odredba stava 1 . člana 55. KZ. U tom smislu, odredba stava 2. istog člana javlja se suvišnom. 
Ukoliko je, pak, zakonodavac imao na umu da isključi mogućnost primene sudskog ublažavanja kazne, onda se formulacija o povratu kao obaveznoj otežavajućoj okolnosti javlja suvišnom.

Povodom ovog pitanja potrebno je dodati i da je institut zabrane ublažavanja kazne izložen oštroj doktrinarnoj kritici. Imajući u vidu pravila o sudskom odmeravanju kazne, kao i načelo slobodnog sudijskog uverenja, koja čine deo naše pravne tradicije, principijelnije bi bilo da je zakonodavac povrat tretirao samo kao obaveznu otežavajuću okolnost, mada i drugi koncept (zabrana sudskog ublažavanja kazne) ima svoje opravdanje. Naime, činjenica da neko lice ponavlja umišljajna krivična dela (znači, ne i nehatna) može dati osnov za zaključak da je drugi put potrebno isključiti mogućnost da sud izrekne kaznu ispod posebnog minimuma ili blažu vrstu kazne (pri tome, odnosi se samo na zabranu sudskog ublažavanja, ne i na ublažavanje po drugim osnovima). U svakom slučaju, zakonodavac bi trebao da opredeli dejstvo običnog povrata ili kao obavezne otežavajuće okolnosti, ili kao okolnosti koja povlači zabranu sudskog ublažavanja kazne, a nikako, kao što je sada u pitanju, da kumulira ova dva dejstva.

\section{Višestruki povrat iz člana 55a $\mathrm{KZ}$}

Prema odredba člana 55a KZ višestruki povrat postoji ukoliko su ispunjeni sledeći uslovi: 1) da je učinjeno umišljajno krivično delo za koje je propisana kazna zatvora; 2) da je učinilac ranije bar dva puta osuđivan na kaznu zatvora za umišljajno krivično delo od najmanje jedne godine; 3) da od dana otpuštanja učinioca sa izdržavanja kazne zatvora do izvršenja novog krivičnog dela nije proteklo pet godina.

Može se u vezi sa prvim uslovom postaviti pitanje: da li se odredba o višestrukom povratu može primeniti ako je za novo krivično delo propisana alternativno novčana kazna uz kaznu zatvora? Drugačije rečeno, da li prvi uslov kod višestrukog povrata podrazumeva da je za novo krivično delo propisana jedino/ isključivo kazna zatvora, ili se pak, može raditi i o inkriminaciji koja je kažnjiva kaznom zatvora i alternativno novčanom kaznom. Ukoliko bi se uzelo da se u slučaju alternativnog propisivanja novčane kazne uz kaznu zatvora (na primer, kod krađe iz člana 203. KZ) ne može primeniti odredba o višestrukom povratu, time bi se redukovao domen primene člana 55a KZ. Ipak, čine se da su suprotni argumenti ,jači“, tj. da se i u tom slučaju može primeniti član 55a KZ. Prvo, jer je u tom slučaju ipak propisana i kazna zatvora; drugo, jer se u članu 55a KZ, kada se govori o dejstvu višestrukog povrata, kaže „sud će izreći kaznu iznad polovine raspona propisane kazne“, što znači da se govori samo o izricanju kazne, 
bez specificiranja njene vrsta. Prema tome, u navedenim situacijama sudu se daje pravo izbora uzmeđu novčane kazne i zatvora, s tim da bi u oba slučaja morao izreći kaznu iznad polovine propisanog raspona.

Drugi uslov višestrukog povrata čini se prilično jasnim - u vreme izvršenja novog krivičnog dela učinilac mora biti već dva puta osuđivan na kaznu zatvora od najmanje jedne godine za umišljajni krivično delo. Naravno, mora se raditi o pravnosnažnim osudama na navedene kazne.

Petogodišnji rok koji je relevantan za ocenu višestrukog povrata teče od dana otpuštanja učinioca sa izdržavanja izrečene kazne. Otpuštanje sa izdržavanja izrečene treba razumeti u smislu odredaba ZIKS-a koji razlikuje nekoliko situacija. Prvo, osuđeni se otpušta iz zavoda onog dana kada mu je istekla kazna, a ukoliko istek kazne pada u subotu, nedelju ili u dane državnih praznika, osuđeni se otpušta poslednjeg radnog dana koji prethodi tim danima (član 178. st. 1. i 2. ZIKS). Drugo, ukoliko se osuđeni otpušta usled amnestije ili pomilovanja zavod je dužan da ga otpusti najkasnije 24 časa nakon prijema rešenja o amnestiji, ako zakonom o amnestiji nije drugačije određeno, odnosno istog dana po prijemu odluke o pomilovanju, a najkasnije u roku od 24 časa (član 183. stav 1. i 2. ZIKS). U ovim slučajevima se smatra da je osuđeni izdržao zatvorsku kaznu. Kao što je rečeno, do gašenja kazne može doći usled njenog izvršenja (tj. izdržavanja kazne zatvora), usled akata političke milosti (amnestija i pomilovanje), ali i zbog zastarelosti izvršenja kazne. Ova poslednja situacija je regulisana KZ. Tako, ukoliko je tokom izdržavanja kazne zatvora došlo do nastupanja apsolutne zastarelosti njenog izvršenja, prema članu 106. stavu 7. KZ započeto izvršenje će se obustaviti. Međutim, za ovaj poslednji slučaj ZIKS ne predviđa kada se osuđeni otpušta sa izdržavanja kazne zatvora. Ttrebalo bi uzeti da se osuđeni otpušta kao i u slučaju amnestije i pomilovanja, tj. najkasnije u roku od 24 časa po prijemu rešenja o obustavi izvršenja kazne. Prema tome, u prethodno navedenim slučajevima kazna zatvora se smatra izvršenom, tako da rok od pet godina relevantan za računanje višestrukog povrata teče od trenutka kada je osuđeni otpušten sa njenog izdržavanja, nezavisno od toga po kojem od navedenih osnova je došlo do otpuštanja.

Dalje, osuđeni se otpušta sa izdržavanja kazne i u slučajevima tzv. prevremenog otpuštanja (ne treba mešati sa uslovnim otpustom). ZIKS je predvideo dva slučaja prevremenog otpuštanja. U prvom slučaju, o prevremenom otpuštanju odlučuje direktor Uprave za izvršenje krivičnih sankcija, koji može prevremeno otpustiti osuđenog sa izdržavanja kazne najviše šest meseci do isteka kazne, ako je izdržao devet desetina kazne, zbog dobrog vladanja osuđenog i postignutih rezultata u programu postupanja, na predlog upravnika zavoda (član 184. ZIKS). 
Ovaj oblik prevremenog otpuštanja ne može se opozvati, tako da se ima smatrati da je osuđeno lice izdržalo kaznu zatvora (Drakić, Milić, 2019: 94). Imajući u vidu rečeno, petogodišnji rok relevantan za ocenu višestrukog povrata teče od kada je osuđeni prevremeno otpušten. U drugom slučaju, o prevremenom otpuštanju odlučuje sudija za izvršenje krivičnih sankcija koji, postupajući po predlogu upravnika zavoda, može prevremeno otpustiti osuđenog sa izdržavanja kazne zatvora najviše 12 meseci do isteka kazne, ako je osuđeni izdržao jednu polovinu kazne zatvora, zbog teške bolesti, teškog invaliditeta ili starosti, ako bi dalje izvršenje kazne predstavljalo nehumano postupanje (član 184a ZIKS). Za ovu situaciju zakonodavac je predvideo mogućnost opoziva odluke kojom je odobreno prevremeno otpuštanje, jer se ono daje iz odgovarajućih zdravstvenih razloga (teška bolest, teški invaliditet ili starost). Osuđeni koji je prevremeno otpušten sa izdržavanja kazne zatvora zbog teške bolesti ili teškog invaliditeta, dužan je da periodično, na svakih 60 dana dostavlja sudiji za izvršenje krivičnih sankcija izveštaj lekara o svom zdravstvenom stanju. Otuda sudija za izvršenje može opozvati odluku kojom je odobreno prevremeno otpuštanje, ako se naknadno utvrdi da nisu postojali ili su prestali da postoje razlozi za prevremeno otpuštanje. Imajući u vidu navedeno, u ovom drugom slučaju se ne bi moglo smatrati da je kazna zatvora sa koje je osuđeni otpušten izdržana. Zbog toga bi u opisanoj situaciji trebalo uzeti da je prevremeno otpušteni izdržao kaznu tek pošto je isteklo njeno trajanje. ZIKS ne predviđa da li se vreme provedeno na prevremenom otpustu uračunava u trajanje zatvorske kazne u slučaju da dođe do njegovog otpusta. U odsustvu preciznije regulative, u slučaju da je osuđeni izvršio krivično delo za vreme prevremenog otpusta koji je određen od strane sudije za izvršenje krivičnih sankcija, trebalo bi uzeti da se ne može primeniti odredba člana 55 a KZ o višestrukom povratu u pogledu petogodišnjeg roka, već u odnosu na učinioca treba primeniti član 62. KZ koji govori o odmeravanju kazne osuđenom licu.

Isto tako, ukoliko je osuđeni pušten na uslovni otpust, na kojem izvrši krivično delo, nema mesta primeni člana 55a KZ, već se imaju primeniti odredbe o opozivu uslovnog otpusta, kao je to prethodno opisano kod običnog povrata.

Rečeno je da se dejstvo višestrukog povrata ogleda u izricanju kazne iznad polovine propisanog raspona za krivično delo. Tako na primer, za krivično delo teške krađe je propisana kazna u rasponu od 1 do 8 godina, što znači da raspon iznosi sedam godina, a njegova polovina 3 godine i 6 meseci. U tom smislu, polovina raspona se dodaje na propisani minimum od jedne godine, tako da kod predmetnog krivičnog dela polovina raspona je 4 godine i 6 meseci. Imajući u vidu da kod višestrukog povrata kazna mora biti preko polovine raspona, to bi u slučaju teške krađe iznosila najmanje 4 godine i 7 meseci (Kolarić, 2019: 32). Na 
ovaj način se, u stvari, sužavaju kazneni rasponi u okviru kojih sud odmerava kaznu a“ (Stojanović, 2020: 42; Đokić, 2019b: 75), kao i ovlašćenje suda da ceni olakšavajuće i otežavajuće okolnosti, jer se ovakvom zakonskom formulacijom kod višestrukog povrata propisuju novi posebni minimumi koji moraju biti iznad polovine raspona propisane kazne (Stojanović, 2020: 42).

Odredba o višestrukom povratu se kritikuje i zbog toga što je protivna načelima pravednosti i srazmernosti, pa time i članu 42. stavu 1. tački 4. KZ (Đokić, 2019: 324). Zaista, upitno je da li je, čak i pod uslovima iz člana 55a KZ, opravdano višestrukim povratnicima po automatizmu izricati kaznu iznad polovine propisanog raspona? To znači da bi učinilac, koji je, na primer, ranije osuđivan dva puta za tešku krađu na zatvor od po jednu godinu dana, a koji je nakon izdržane kazne učinio tešku krađu na naročito drzak način tako što je od lica koje spava oduzeo novčanicu od 50 evra, ${ }^{14}$ morao biti osuđen na najmanje četiri godine i sedam meseci zatvora. Teško da se ovo može uklopiti u princip(e) pravednosti i srazmernosti.

\section{Specijalni povrat iz člana 57. stava $3 . \mathrm{KZ}$}

Član 57. KZ posvećen je granicama ublažavanja kazne. U njegovom stavu 3. je propisano da se učiniocu ne može ublažiti kazna ako je već osuđivan za isto ili istovrsno krivično delo. Ovo je sve od regulative specijalnog povrata u našem KZ. Kao i kod svake druge vrste povrata, tako i kod specijalnog povrata treba uzeti da je za njegovo postojanje potrebno da je učinilac u vreme izvršenja novog krivičnog dela već pravnosnažno osuđivan za isto ili istovrsno krivično delo.

Rešenje je, kao što se da primetiti, nesistematično i šturo. Pre svega, specijalnom povratu ne bi trebalo da bude mestu u odredbi koja je posvećena granicama ublažavanja kazne, naročeto ne nakon što je zakonodavac rešio da pojedine forme povrate (obični i višestruki) reguliše u posebnim članovima. S druge strane, štura regulativa specijalnog povrata omogućava njegovu zaista široku primenu. Naime, kod specijalnog povrata relevantno je samo da se radi o istom ili istovrsnom krivičnom delu. U tom smislu, u obzir dolaze kako umišljajna tako i nehatna dela (?). Moguće je da je i novo i prethodno delo nehatno; da je pret-

14 U sudskoj praksi se ovo tretira krađom na naročito drzak način. U presudi Okružnog suda u Beogradu K. 56/95 od 25.01.1995. godine stoji: „Krađa izvršena na posebno drzak način postoji kada je učinilac u čekaonici železničke stanice ujutro u četiri sata oštećenom, dok je spavao na klupi, seo pored njega, iz unutrašnjeg džepa sakoa izvadio novčanik sa novcem i udaljio se“" (Đurđić, Jovašević, 2003: 146). Prof. Stojanović navodi, pozivajući se na neke sudske odluke, da se veoma često uzima da postoji krađa na naročito drzak način kada je stvar oduzeta od oštećenog koji spava (Stojanović, 2009: 508). 
hodno delo bilo nehatno (na primer nehatni oblik ugrožavanja javnog saobraćaja), a novoučinjeno umišljajno (umišljajni oblik ugrožavanja javnog saobraćaja) i obratno. U svim ovim situacijama, isključena je mogućnost ublažavanja kazne.

Ono što je posebno problematično jeste to što kod specijalnog povrata $z a$ konodavac nije odredio koji je to period (rok) od ranije osude ili izdržane kazne pa do novoučinjenog krivičnog dela relevantan za njegovo postojanje. To navodi na zaključak da se kod specijalnog povrata ranija osuđivanost za isto ili istovrsno delo razmatra sve dok ne nastupi rehabilitacija, tj. dok ne dođe do brisanja ranije osude. Ovakav koncept, međutim, može voditi rešenjima koja su prilično nepravična, pa time i protivna principu pravednosti i srazmernosti iz člana 42. stava 1. tačke 4. KZ. Na primer, neko lice je osuđeno, a potom i izdržalo kaznu za koju nije moguća rehabilitacija, a to su sve osude na zatvor preko pet godina; ako takvo lice i nakon više decenija učini isto ili istovrsno delo, njemu se kazna ne može ublažiti!?

Povodom zabrane ublažavanja u slučaju višestrukog povrata iz člana 57. stava 3. KZ (kao i kod zabrane ublažavanja za taksativno navedena krivična dela iz stava 2. istog člana) otvara se pitanje da li se ona odnosi samo na sudsko ili $i$ na sudsko i na zakonsko ublažavanje kazne? Očigledno je samo da se zabrana ne odnosi na slučaj kada se učinilac može osloboditi od kazne, a sud ga iste ne oslobodi, jer je to izričito normirano u članu 57. stavu 4. KZ.

Pitanje je od izuzetnog praktičnog značaja. Na primer, da li se učiniocu krađe u pokušaju koji je ranije osuđivan za isto delo kazna može ublažiti ili ne? Nesporno je da je u pitanju specijani povratnik, ali je i fakat da je novoučinjeno krivično delo ostalo u pokušaju, a za pokušaj je zakonom predviđena mogućnost ublažavanja kazne. Da li će u ovoj situaciji sud dati prednost zabrani ublažavanja kazne na osnovu člana 57. stav 3. KZ, ili ipak može na osnovu zakonskih odredaba o kažnjivosti pokušaja kaznu ublažiti?

Iz jezičkog tumačenja proističe da se zabrana odnosi kako na zakonsko, tako i na sudsko ublažavanje kazne. Da je zakonodavac hteo mogao je izričito predvideti da se zabrana ublažavanja odnosi samo na sudsko ublažavanja. U literaturi se, međutim, iznose drugačiji arumenti po kojima se, i pored izričite odredbe člana 57. stava 3. KZ, zabrana odnosi samo na sudsko, ne i na zakonsko ublažavanje kazne. Naime, smatra se, s pravom, da se kriminalno politički teško može braniti rešenje koje isključuje mogućnost primene zakonskih osnova za ublažavanje kazne, čime se izjednačava kažnjavanje za pokušano i dovršeno krivično delo, ne uvažava bitno smanjena uračunljivost itd. Drugačije rečeno, ukoliko bi se prihvatilo da se zabrana odnosi i na zakonsko ublažavanje, time bi se, u stvari, stavile van snage sve one odredbe opšteg dela KZ koje u određenim slučajevima predviđaju mogućnost ublažavanja kazne (Stojanović, 2016: 318) 
Iako je navedena argumentacija „na mestu“, pitanje je da li je navedeno tumačenje ima valjano uporište u KZ, naročito posle izmene odredbe člana 55. $\mathrm{KZ}$ o povratu. Ovde bi trebalo podsetiti da odredba člana 57. stav 3 . KZ o specijalnom povratu egzistira kod nas više od jedne decenije (od 2009.), te da se nije našlo za shodno da se ista revidira u pogledu svog pravnog dejstva tako što će se izričito propisati da se zabrana odnosi samo na sudsko ublažavanje kazne. Pri tome, odredba člana 57. stav 3. je nekoliko puta menjana u svojoj stilistici (prvo je stajalo ,isto“, potom ,istovrsno“ i na kraju ,isto ili istovrsno“ krivično delo), ali ne i povodom njenog dejstva iako se u relevantnoj literaturi na to ukazivalo.

Ako se sada pogleda normativno uređene zabrane ublažavanja kazne, uočiće se dva pristupa: prvi, kod specijalnog povrata (i taksativno nabrojanih krivičnih dela), koji postoji od 2009., gde je zakonodavac samo isključio zabranu ublažavanja, ne specificirajući da li se radi o sudskom ili zakonskom (član 57. st. 2. i 3. KZ); drugi, kod običnog povrata, koji postoji od 2019., gde je zakonodavac naznačio da je zabranjeno samo sudsko ublažavanje (član 55. stav 2. KZ). Ovako stanje stvari govori u prilog tezi da je argumentacija po kojoj se kod specijalnog povrata zabrana odnosi samo na sudsko ublažavanje kazne teško održiva, ma koliko ona bila opravdana i ,jaka“. Ipak zakonodavac i pored brojnih izmena $\mathrm{KZ}$ istrajava na tome da je kod specijalnog povrata isključeno ublažavanje kazne, bez specificiranja da je u pitanju sudsko ublažavanje kazne.

Imajući u vidu da zakonodavac normira obični i višestruki povrat, upitnom se javlja dalja potreba postojanja člana 57. stava 3. KZ. Kao što je rečeno, od specijalnog povrata nisu izuzeta ni nehatna krivična dela, tako da i u tom slučaju važi zabrana ublažavanja kazne, što nema svoje kriminalno-političko opravdanje. Ako se već želi zadržati konstrukcija specijalnog povrata onda se isti mora preciznije odrediti i to u posebnom zakonskom članu. Nije dovoljno navesti da je potrebno da je učinilac ranije osuđivan za isto ili istovrsno krivično delo. U najmanju ruku specijalni povrat bi se morao ograničiti na umišljajna krivična dela, mada bi tada bila sporna potreba njegovog postojanja, jer to već pokrivaju postojeće forme povrata. Dalje, morao bi se predvideti i rok/period relevantan za ocenu specijalnog povrata, kao što je to predviđeno za obični i višestruki povrat. Takođe, morala bi se iznaći odgovarajuća specifičnost u pogledu sankcionisanja specijalnog povrata, koja bi se razlikovala od onih mogućnosti koje su date kod običnog i višestrukog povrata, mada i u tom pogledu teško da se „šta novo“ može ponuditi imajući u vidu šta odredbe čl. 55. i 55a KZ pružaju. Upravo prethodno rečeno navodi na zaključak da je ova forma povrata pored postojećih suvišna. 


\section{Umesto zaključka}

Postojeća regulativa povrata i njegovih formi u KZ Srbije je svakako na liniji pooštravanja krivičnopravne prinude. Naročito je problematičan specijalni povrat, jer je postojeće rešenje nesistematično i šturo, a s obzirom na postojanje običnog i višestrukog povrata, isti se javlja i suvišnim. Na višestruki povrat se u domaćoj literaturi gleda sa priličnom skepsom. Jer, ,iskustvo je pokazalo da jednostran pristup koji se svodi isključivo na strože kažnjavanje učinioca za novo delo zbog postojanja ranije (višestruke) osuđivanosti nema zadovoljavajuće učinke“ (Đokić, 2019b: 76). Navodi se da je ovaj oblik povrata „vaskrso i pored činjenice da je u fazi umiranja u mnogim zemljama“ (Kolarić, 2019: 31). Zasigurno je da višestruki povrat ne uvažava principe pravednosti i srazmernosti koji su izričito proklamovani u članu 42. KZ, kao i da sužava mogućnosti suda prilikom odmeravanja kazne, jer svojim pravnim dejstvom ,podiže“ posebne minimume zahtevajući da se višestrukom povratniku, uz ispunjenost ostalih uslova iz člana 55a KZ, izrekne kazna iznad polovine raspona propisane kazne. Za obični povrat se može reći da ima svoje kriminalno-političko opravdanje, s tim da je zakonodavac trebao da njegovo dejstvo svede ili na obaveznu otežavajuću okolnost, ili na zabranu ublažavanja kazne, a ne da propiše oba ova dejstva, o čemu je bilo reči u prethodnom tekstu.

Na kraju je potrebno istaći i to da se ranija osuđivanost nekada ne može ceniti na osnovu odredaba o običnom, višestrukom ili specijalnom povratu, ali može na osnovu člana 54. KZ, tj. prema pravilima o odmeravanju kazne. Na primer, učinilac nekog krivičnog dela (bilo umišljajnog bilo nehatnog) je ranije osuđivan za nehatno (heterogeno) krivično delo; ili učinilac nehatnog krivičnog dela je ranije osuđivan za (heterogeno) umišljajno krivično delo. U ovim slučajevima nema mesta primeni odredaba o običnom i višestrukom povratu (jer je bar jedno od krivičnih dela nehatno), niti ima mesta primeni pravila o specijalnom povratu (s obzirom da je reč o heterogenim krivičnim delima), ali bi se ranija osuđivanost mogla ceniti u okviru ,ranijeg života“ učinioca, kao jedne od okolnosti koja je navedena u članu 54. KZ.

U svakom slučaju problematika povrata kao takvog je u krivičnom zakonodavstvu Srbije „pokrivena“" sa više odredaba koje imaju različita pravna dejstva, mada mnoge od njih stvaraju brojne nedoimice kako na polju njihovog normativnog uređenja, tako i povodom njihove kriminalno-političke opravdanosti. O tome bi se moralo voditi računa u nekim budućim novelama KZ. 


\section{Literatura}

- Brkić, S. (2018) Postupak za izricanje mera bezbednosti obaveznog psihijatrijskog lečenja i njegov odnos prema opštem i skraćenom krivičnom postupku. Zbornik radova Pravnog fakulteta u Novom Sadu, 2, str. 477-490.

- Ćorović, E. (2015) Sistem krivičnih sankcija Republike Srbije. Novi Pazar Niš: Autorsko izdanje - Sven.

- Ćorović, E. (2020) Kritički osvrt na neke odredbe Krivičnog zakonika Srbije o odmeravanju i zabrani ublažavanja kazne. U: M. Simović (ur.) Krivično zakonodavstvo i prevencija kriminaliteta (norma i praksa). Laktaši-Beograd: GrafoMark - Srpsko udruženje za krivičnopravnu teoriju i praksu, str. 159-176.

- Delić, N. (2010) Zabrana (isključenje) ublažavanja kazne u određenim slučajevima. U: Ignjatović Đ. (ur.) Stanje kriminalieta u Srbiji i pravna sredstva reagovanja, IV deo. Beograd: Pravni fakultet Univerziteta u Beogradu.

- Drakić, D., Milić, I. (2019) Osnovi krivičnog izvršnog prava. Novi Sad: Pravni fakultet u Novom Sadu.

- Đokić, I. (2019) Istorijski osvrt na institut povrata u srpskom (jugoslovenskom) krivičnom pravu. U: Ignjatović Đ. (ur.) Kaznena reakcija u Srbiji, IX deo. Beograd: Pravni fakultet Univerziteta u Beogradu, str. 308-326.

- Đurđić, V., Jovašević, D. (2003) Praktikum za krivično pravo: Posebni deo. Beograd: Službeni glasnik.

- Jocić, D. (2019) Povrat kao okolnost kod odmeravanja kazne. U: Bejatović S. (ur.) Izmene u krivičnom zakonodavstvu $i$ status nosilaca pravosudnih funkcija i adekvatnost državne reakcije na kriminalitet (međunarodni pravni standardi $i$ stanje u Srbiji)/LIX redovno godišnje savetovanja Udruženja (Zlatibor). Beograd: Srpsko udruženje za krivičnopravnu teoriju i praksu-Intermex, str. 230-241.

- Kolarić, D. (2019) Krivični zakonik i (ne)adekvatnost državne reakcije na kriminalitet (sadašnje stanje i nova rešenja). U: Bejatović S. (ur.) Izmene u krivičnom zakonodavstvu $i$ status nosilaca pravosudnih funkcija i adekvatnost državne reakcije na kriminalitet (međunarodni pravni standardi i stanje u Srbiji)/ LIX redovno godišnje savetovanja Udruženja (Zlatibor). Beograd: Srpsko udruženje za krivičnopravnu teoriju i praksu-Intermex, str. 22-41.

- Stojanović, Z. (2009) Komentar Krivičnog zakonika. Beograd: Služeni glasnik.

- Stojanović, Z. (2016) Krivično pravo: Opšti deo. Beograd: Pravna knjiga.

- Stojanović, Z. (2020) Nova rešenja u Krivičnom zakoniku Srbije (predgovor). U: Krivični zakonik, prema stanju zakonodavstva od 1. decembra 2019. godine. Beograd: Službeni glasnik. 


\section{RECIDIVISM WITHIN THE CRIMINAL CODE OF SERBIA: CRITICAL REVIEW OF ITS NORMATIVE REGULATION}

Latest changes of the Criminal code of Serbia from May 2019, which went into force on December 1 of the same year, changed the concept of recidivism which existed within our legal system until this point. Namely, in addition to the so-called ,regular" recidivism, which is now regulated in a completely different way compared to the previous legislation, multiple recidivism is now a particular legal category. Regulating these two forms of recidivism, the Criminal code of Serbia also recognizes special recidivism, which is regulated within provisions regarding the mitigation of punishment, more precisely as one a legal basis which excludes the possibility to mitigate the punishment. Legal regulation of the aforementioned types of recidivism is not very accurate and it can create certain dilemmas when these provisions are applied in practice. Hence, this paper will point out the weaknesses and illogicality of the normative forms of certain types of recidivism, all with the purpose of improving their forms of legal regulation.

Key words: recidivism, multiple recidivism, special recidivism. 